\title{
IMPLEMENTASI DATAMINING PADA KASUS TENAGA LISTRIK YANG DIBANGKITKAN BERDASARKAN PROVINSI
}

\author{
Afrina Wati ${ }^{1}$, Iin Indriani ${ }^{2}$, Tira Sifrah Saragih Manihuruk ${ }^{3}$, Sintya ${ }^{4}$, Ivo Yohana Manurung, ${ }^{5}$ Agus Perdana \\ Windarto ${ }^{6}$
}

${ }^{1}$ Sistem Informasi, STIKOM Tunas Bangsa, Pematangsiantar, Indonesia

Email: ${ }^{1}$ afrinawatihsb@gmail.com, ${ }^{2}$ agus.perdana@amiktunasbangsa.ac.id

\begin{abstract}
Abstrak
Indonesia merupakan salah satu negara pengguna energi tenaga listrik yang sangat vital. Semakin berkembangnya dunia teknologi dan informasi dalam penggunaannya tidak luput dari akses tenaga listrik. Penelitian ini membahas tentang Implementasi Datamining Pada Kasus Tenaga Listrik yang Dibangkitkan Berdasarkan Provinsi. Meningkatnya kebutuhan dalam penggunaan tenaga listrik dari masa ke masa tidak pernah luput dari perhatian dan naungan pemerintah. Sumber data pada penelitian ini diakses dari situs resmi pemerintah Indonesia yaitu Badan Pusat Statistik (http://www.bps.go.id). Data yang digunakan dalam penelitian ini yaitu data dari tahun 2011-2017 yang terdiri dari 33 provinsi yang ada di negara Indonesia. Dalam analisa penelitian ini menggunakan 3 (tiga) tingkat cluster yaitu pertama cluster tingkat tinggi (C1), kedua cluster tingkat sedang (C2) dan ketiga cluster tingkat rendah (C3). Sehingga hasil akhir dari analisis penelitian kasus Tenaga Listrik yang Dibangkitkan Berdasarkan Provinsi diperoleh data dan informasi baru yakni provinsi cluster tinggi sebanyak 2 provinsi yaitu Jawa Timur dan Banten, provinsi cluster sedang sebanyak 4 provinsi yaitu Sumatera Utara, Sumatera Selatan, Jawa Barat dan Jawa Tengah sedangkan provinsi cluster rendah sebanyak 27 di provinsi lainnya. Hasil analisis dari penelitian ini dapat dijadikan sebagai masukan bagi pemerintah dan Perusahaan Listrik Negara (PLN), agar menjadikan provinsi kategori cluster rendah sebagai prioritas utama dalam meningkatkan pertumbuhan pembangkit tenaga listrik serta lebih interaktif dalam pemanfaatan energi listrik secara efektif dan efisien.
\end{abstract}

Kata Kunci: Data Mining, K-Means, Clustering, Energi, Tenaga Listrik, Provinsi

\begin{abstract}
Indonesia is one of the most vital electric energy users. The development of the world of technology and information in its use does not escape from access to electricity. This study discusses the Implementation of Datamining in the Case of Electric Power Generated by Province. The increasing need for electricity usage from time to time has never escaped the attention and auspices of the government. The data source in this study was accessed from the official website of the Indonesian government, namely the Central Statistics Agency (http://www.bps.go.id). The data used in this study are data from 2011-2017 which consists of 33 provinces in Indonesia. In the analysis of this study using 3 (three) cluster levels, namely the first high level cluster (C1), the second moderate level cluster (C2) and the third low level cluster (C3). So that the final results of the analysis of the case study of Electric Power Generating by Province obtained new data and information, namely the high cluster province of 2 provinces namely East Java and Banten, the medium cluster province of 4 provinces namely North Sumatra, South Sumatra, West Java and Central Java while low cluster provinces as much as 27 in other provinces. The results of the analysis of this study can be used as input for the government and the State Electricity Company $(P L N)$, in order to make the province of the highest cluster category a top priority in increasing the growth of power plants as well as being more interactive in the utilization of electricity effectively and efficiently.
\end{abstract}

Keywords: Data Mining, K-Means, Clustering, Energy, Electric Power, Province

\section{PENDAHULUAN}

Tenaga listrik adalah daya dan kemampuan yang berasal dari proses pergesekan mekanis dan kimiawi yang menghasilkan aliran pergerakan electron serta disalurkan melalui perantara alat penghantar berupa kabel yang dapat diubah menjadi energi cahaya, gerak, panas, dan bunyi sehingga dapat digunakan secara efektif dan efisien untuk mempermudah kinerja manusia. Di era teknologi dan praktis modern, manusia menjadikan tenaga listrik sebagai kebutuhan primer. Tingginya tingkat kebutuhan teknologi dan informasi mendorong pemerintah dan perusahaan listrik untuk melakukan pembangkitan listrik agar dapat memenuhi pertumbuhan permintaan tenaga listrik dengan menciptakan pusat listrik baru dan berbagai bentuk energi sebagai pendukungnya. Pembangunan pembangkit tenaga listrik pasti memerlukan biaya tinggi dan jangka waktu yang lama. Dengan pengaturan pemakaian tenaga listrik secara efisien baik dalam besaran maupun waktunya memberikan manfaat bagi perusahaan listrik dan pelanggan pengguna tenaga listrik yaitu: (a) menghemat biaya bahan bakar, biaya operasi dan biaya perawatan, (b) meminimalisir pembangunan pembangkit listrik dan jaringan listrik untuk memenuhi permintaan kenaikan tenaga listrik, (c) menjaga kapasitas ketersediaan tenaga listrik, (d) mengurangi dampak pemanasan global (global warming), (e) meningkatkan efektivitas kesehatan tubuh, (f) menghemat sumber daya alam. Pada tahun 2017, jumlah pelanggan perusahaan listrik negara mencapai 66,63 juta pelanggan. Persentase kenaikan mencapai 3,65 persen dari tahun 2016 yaitu mencapai 64,28 juta. Berdasarkan data Perusahaan Listrik Negara (PLN), pada tahun 2012-2016 jumlah pelanggan tenaga listrik rata-rata tumbuh 7,45 persen per tahun. Peningkatan pembangkitan tenaga listrik menandakan semakin bertambahnya konsumsi listrik per kapita diseluruh dunia serta menunjukkan naiknya standar kehidupan manusia.

Sumber data pada penelitian ini diperoleh dari Badan Pusat Statistik (BPS) yang di akses melalui situs http://www.bps.go.id. Pada penelitian terdahulu, banyak metode ilmu komputer yang digunakan oleh peneliti dalam menyelesaikan permasalahan secara efisien yang bersifat kompleks yaitu metode datamining[1][2][3], metode 
fuzzy[4], metode sistem pendukung keputusan[5], metode jaringan saraf tiruan[6]. Pada penelitian ini peneliti membahas kasus tentang Tenaga Listrik yang dibangkitkan berdasarkan Provinsi dengan menggunakan metode datamining K-Means Clustering sebagai penyelesaian. Dalam proses cluster menggunakan 3 (tiga) tingkat cluster yaitu cluster tingkat tinggi (C1), cluster tingkat sedang (C2) dan cluster tingkat rendah (C3). Sehingga hasil akhir dari analisis penelitian kasus Tenaga Listrik yang Dibangkitkan Berdasarkan Provinsi diperoleh data dan informasi baru yakni provinsi cluster tinggi sebanyak 2 provinsi, provinsi cluster sedang sebanyak 4 provinsi dan provinsi cluster rendah sebanyak 27 provinsi. Hasil analisis dari penelitian ini dapat dijadikan sebagai masukan bagi pemerintah dan Perusahaan Listrik Negara (PLN), agar menjadikan provinsi kategori cluster provinsi terendah sebagai prioritas utama dalam meningkatkan pertumbuhan pembangkit tenaga listrik serta lebih interaktif dalam pemanfaatan energi listrik secara efektif dan efisien.

\section{TEORITIS}

\subsection{Tenaga Listrik}

Tenaga listrik adalah daya dan kemampuan yang berasal dari proses pergesekan mekanis dan kimiawi yang menghasilkan aliran pergerakan electron serta disalurkan melalui perantara alat penghantar berupa kabel yang dapat diubah menjadi energi cahaya, gerak, panas, dan bunyi sehingga dapat digunakan secara efektif dan efisien untuk mempermudah kinerja manusia. Semakin bertambahnya populasi manusia mengakibatkan pertumbuhan permintaan tenaga listrik semakin meningkat. Hal itulah yang mendorong pemerintah dan perusahaan listrik negara harus melakukan regenerasi pembangkit tenaga listrik.

\subsection{Datamining}

Data, informasi dan pengetahuan tidak luput dari interaksi manusia setiap harinya. Berbagai macam sektor bidang data yang telah diolah dan dianalisis oleh peneliti untuk memperoleh ilmu pengetahuan yang lebih kompleks. Datamining atau knowledge discovery adalah teknik komputer yang digunakan untuk mengelompokkan data sesuai kesamaan yang ditentukan dengan proses pembagian pola data[3]. K-Means merupakan salah satu algoritma yang prosedurnya berbentuk sederhana yang berguna untuk partisi atau membagi data sesuai kesamaan yang telah ditentukan ke dalam bagian dua kelompok atau lebih. Algoritma ini akan mengklasifikasikan data ke dalam bagian suatu kelompok, data yang memiliki karakter yang sama akan masuk dalam kelompok yang sama dan begitu juga sebaliknya pada kelompok yang berbeda[7].

\subsection{Clustering}

Clustering merupakan proses klasifikasi data atau objek secara otomatis ke dalam suatu kelompok (cluster) yang didasarkan pada informasi yang ditemukan dalam data yang menggambarkan hubungan antar objek. Masukan (input) dalam prosedur clustering yaitu set data dan persaamaan serta perbedaan ukuran antara dua data. Sedangkan hasil (output) dari prosedur clustering adalah sejumlah kelompok yang membentuk struktur partisi dari kumpulan data[2].

\section{METODOLOGI PENELITIAN}

\subsection{Metode Pengumpulan Data}

Implementasi datamining pada kasus klasifikasi provinsi terhadap tenaga listrik yang dibangkitkan sangat diperlukan data terkait sebagai penunjang analisis. Pada penelitian ini menggunakan sumber data yang diakses pada situs resmi Nasional Badan Pusat Statistik (http://www.bps.go.id). Data yang digunakan pada penelitian ini adalah banyaknya tenaga listrik (GWh) yang dibangkitkan pada tahun 2011-2017 di 33 provinsi di Indonesia. Variable yang digunakan adalah nilai jumlah daya (GWh) tenaga listrik yang dibangkitkan pada setiap provinsi dari tahun 20112017. Data tersebut kemudia diolah menjadi 3 tingkat cluster yakni provinsi yang memiliki tingkat pembangkit tenaga listrik tinggi (C1), provinsi yang memiliki tingkat pembangkit tenaga listrik sedang (C2) dan provinsi yang memiliki tingkat pembangkit tenaga listrik rendah(C3).

\subsection{Tahap Pengolahan Data}

Data yang diperoleh akan diolah terlebih dahulu. Pada tahap pengolahan data sebelumnya, data setiap provinsi dijumlah dengan setiap sudutnya sehingga sudah diperoleh nilai pada tahapan ini yang akan diproses untuk mendapatkan hasil pengelompokkan data pada tahap clustering[8].

\subsection{Tahap Clustering}

Analisis clustering dalam prosedur klasifikasi data atau objek dalam suatu set data ke dalam sejumlah kelompok yang kesamaan datanya lebih besar dari kesamaan data kelompok lainnya yang bertujuan untuk meminimalisir fungsi objective yang diset dalam pemrosesan secara sederhana akan meminimalisir variasi pada suatu kelompok dan 
memaksimalkan variasi antar kelompok[9]. Dalam memudahkan penentuan cluster dibutuhkan flowchart yang berfungsi sebagai rangkaian alur untuk mempermudah proses perhitungan berdasarkan data yang telah tersedia.

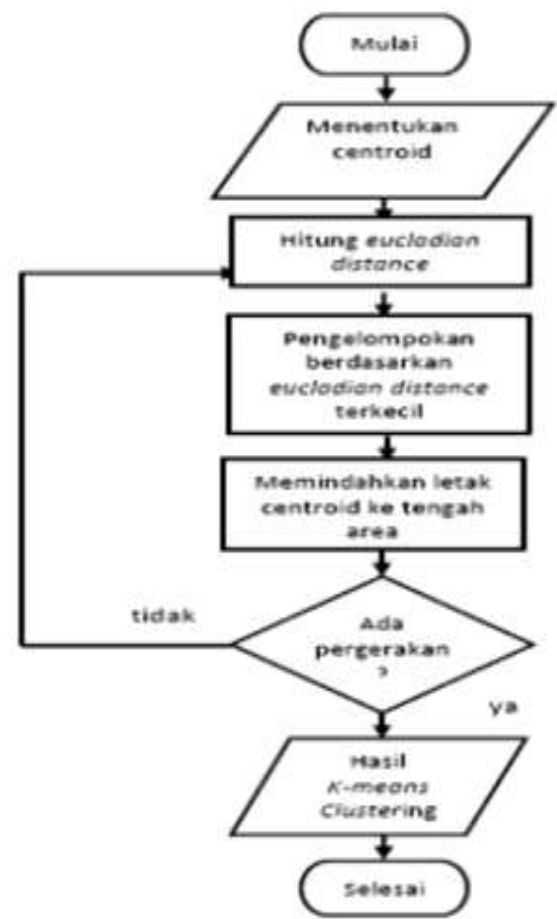

Gambar 1. Flowchart Clustering

\subsection{Tahap Analisis}

Pada tahap ini akan dianalisis data tenaga listrik yang dibangkitkan berdasarkan provinsi. Data yang diperoleh akan diolah dengan menggunakan perhitungan bobot dari setiap indeks. Pada tahapan sebelumnya, data telah di kelompokkan ke dalam 3 (tiga) cluster yaitu tingkat pembangkit tenaga listrik tinggi (C1), tingkat pembangkit tenaga listrik sedang (C2), dan tingkat pembangkit tenaga listrik rendah (C3). Pada tahap inilah data diananlisis hasilnya[1].

\section{ANALISA DAN PEMBAHASAN}

Dalam proses analisis clustering, sumber data yang telah diambil dihitung terlebih dahulu berdasarkan hasil rata-rata dari nilai jumlah daya atau kekuatan tenaga listrik yang telah dibangkitkan di 34 provinsi di Indonesia pada tahun 2011-2017.

Tabel 1. Data Provinsi Pembangkitan Tenaga Listrik, 2011-2017

\begin{tabular}{lcccccc}
\hline \multirow{2}{*}{ Provinsi } & \multicolumn{5}{c}{ Tenaga Listrik yang Dibangkitkan Menurut Provinsi (GWh) } \\
\cline { 2 - 7 } & $\mathbf{2 0 1 1}$ & $\mathbf{2 0 1 2}$ & $\mathbf{2 0 1 3}$ & $\mathbf{2 0 1 4}$ & $\mathbf{2 0 1 5}$ & $\mathbf{2 0 1 7}$ \\
\hline Aceh & 794.16 & 534.8 & 522.89 & 582.06 & 618.26 & 568.2 \\
Sumatera Utara & 15342.39 & 16402.98 & 17459.73 & 18028.3 & 18876.59 & 18544.99 \\
Sumatera Barat & 287.05 & 169.73 & 185.73 & 179.47 & 182.69 & 89.28 \\
Riau & 742.9 & 634.56 & 811.3 & 892.63 & 969.73 & 1032.83 \\
Jambi & 18.7 & 108.15 & 137.62 & 127.89 & 134.31 & 124.19 \\
Sumatera Selatan & 11869.97 & 14033.65 & 14639.61 & 15738.07 & 16431.48 & 16955.88 \\
Bengkulu & 84.2 & 88.63 & 75.25 & 81.04 & 82.87 & 80.73 \\
Lampung & 271.57 & 41.53 & 40.56 & 40.59 & 40.55 & 40.6 \\
Kep. Bangka Belitung & 605.14 & 744.45 & 802.32 & 927.95 & 939.41 & 974.12 \\
Kep. Riau & 2155.14 & 2345.35 & 2166.16 & 3530.02 & 2830.82 & 2275.74 \\
DKI Jakarta & 3566.51 & 5526.4 & 5433.79 & 4115.58 & 3408.6 & 16070.82 \\
Jawa Barat & 16089.53 & 17378.85 & 21615.84 & 20849.37 & 20617.92 & 37801.93 \\
Jawa Tengah & 28144.95 & 27271.44 & 27916.22 & 27133.45 & 25690.27 & 39579.73 \\
Jawa Timur & 51798.98 & 51753.79 & 54548.64 & 56631.27 & 52624.96 & 53868.24 \\
Banten & 39459.85 & 46317.37 & 52860.36 & 63695.13 & 70279.07 & 46111.5
\end{tabular}




\begin{tabular}{lcccccc} 
Bali & 573.6 & 1951.83 & 2271.2 & 2374.48 & 1919.8 & 3564.45 \\
Nusa Tenggara Barat & 958.37 & 1118.46 & 1311.72 & 1476.01 & 1558.03 & 1563.41 \\
Nusa Tenggara Timur & 531.9 & 643.87 & 717.66 & 730.93 & 820.2 & 600.32 \\
Kalimantan Barat & 1662.91 & 1852.69 & 2116.47 & 2225.89 & 2340.32 & 1609.28 \\
Kalimantan Tengah & 554.12 & 611.26 & 615.2 & 602.42 & 556.67 & 369.11 \\
Kalimantan Selatan & 2063.97 & 2331.42 & 2690.52 & 3124.21 & 3314.14 & 3933.49 \\
Kalimantan Timur & 2560.09 & 2675.06 & 3636.9 & 3063.27 & 2450.57 & 3769.59 \\
Kalimantan Utara & 168.83 & 164.44 & 162.31 & 206.06 & 70.48 & 184.58 \\
Sulawesi Utara & 1185.8 & 1841.21 & 1863.31 & 1916.15 & 1959.76 & 1937.36 \\
Sulawesi Tengah & 731.49 & 803.14 & 916.27 & 1768.15 & 1580.22 & 1720.51 \\
Sulawesi Selatan & 3848.83 & 4237.42 & 4233.85 & 5254.27 & 5978.87 & 5878.51 \\
Sulawesi Tenggara & 499.1 & 629.22 & 236.83 & 273.37 & 846.29 & 873.8 \\
Gorontalo & 251.45 & 209.48 & 174.99 & 233.59 & 291.12 & 115.76 \\
Sulawesi Barat & 9.25 & 7.68 & 7.42 & 18.01 & 18.9 & 44.25 \\
Maluku & 471.33 & 608.88 & 524.93 & 751.9 & 781.38 & 620.77 \\
Maluku Utara & 156.85 & 107.89 & 245.01 & 138.5 & 170.35 & 238.21 \\
Papua Barat & 337.94 & 381.04 & 415.6 & 324.34 & 447.95 & 713.88 \\
Papua & 600.44 & 678.74 & 850.71 & 974.65 & 917.48 & 805.28 \\
\hline
\end{tabular}

Sumber Data : Badan Pusat Statistik (http://www.bps.go.id)

Hasil akumulasi data berdasarkan kriteria yang telah ditentukan tertera pada tabel 2.

Tabel 2. Data Akumulasi Tenaga Listrik yang Dibangkitkan Menurut Provinsi (GWh)

\begin{tabular}{clc}
\hline No. & \multicolumn{1}{c}{ Provinsi } & Jumlah $(\mathbf{G W h})$ \\
\hline 1 & Aceh & 3620.37 \\
2 & Sumatera Utara & 104654.98 \\
3 & Sumatera Barat & 1093.95 \\
4 & Riau & 5083.95 \\
5 & Jambi & 650.86 \\
6 & Sumatera Selatan & 89668.66 \\
7 & Bengkulu & 492.72 \\
8 & Lampung & 475.40 \\
9 & Kep. Bangka Belitung & 4993.39 \\
10 & Kep. Riau & 15303.23 \\
11 & DKI Jakarta & 38121.70 \\
12 & Jawa Barat & 134353.44 \\
13 & Jawa Tengah & 175736.06 \\
14 & Jawa Timur & 321225.88 \\
15 & Banten & 318723.28 \\
16 & Bali & 12655.36 \\
17 & Nusa Tenggara Barat & 7986.00 \\
18 & Nusa Tenggara Timur & 4044.88 \\
19 & Kalimantan Barat & 11807.56 \\
20 & Kalimantan Tengah & 3308.78 \\
21 & Kalimantan Selatan & 17457.75 \\
22 & Kalimantan Timur & 18155.48 \\
23 & Kalimantan Utara & 956.70 \\
24 & Sulawesi Utara & 10703.59 \\
25 & Sulawesi Tengah & 7519.78 \\
26 & Sulawesi Selatan & 29431.75 \\
27 & Sulawesi Tenggara & 3358.61 \\
28 & Gorontalo & 1276.39 \\
29 & Sulawesi Barat & 105.51 \\
30 & Maluku & 3759.19 \\
31 & Maluku Utara & 1056.81 \\
32 & Papua Barat & 2620.75 \\
33 & Papua & 4827.30 \\
\hline & & \\
& & \\
\hline
\end{tabular}

Nilai yang dihasilkan dari akumulasi data dari seluruh provinsi, selanjutnya akan diproses dengan software RapidMiner dalam tahap clustering data menggunakan 3 cluster dengan menerapkan algoritma k-means.

\subsection{Input Data}


Data yang telah diperoleh selanjutnya akan diuji ke tool RapidMiner dengan 3(tiga) cluster data. Sehingga hasil dari pengujian tersebut tampak pada gambar 2 .

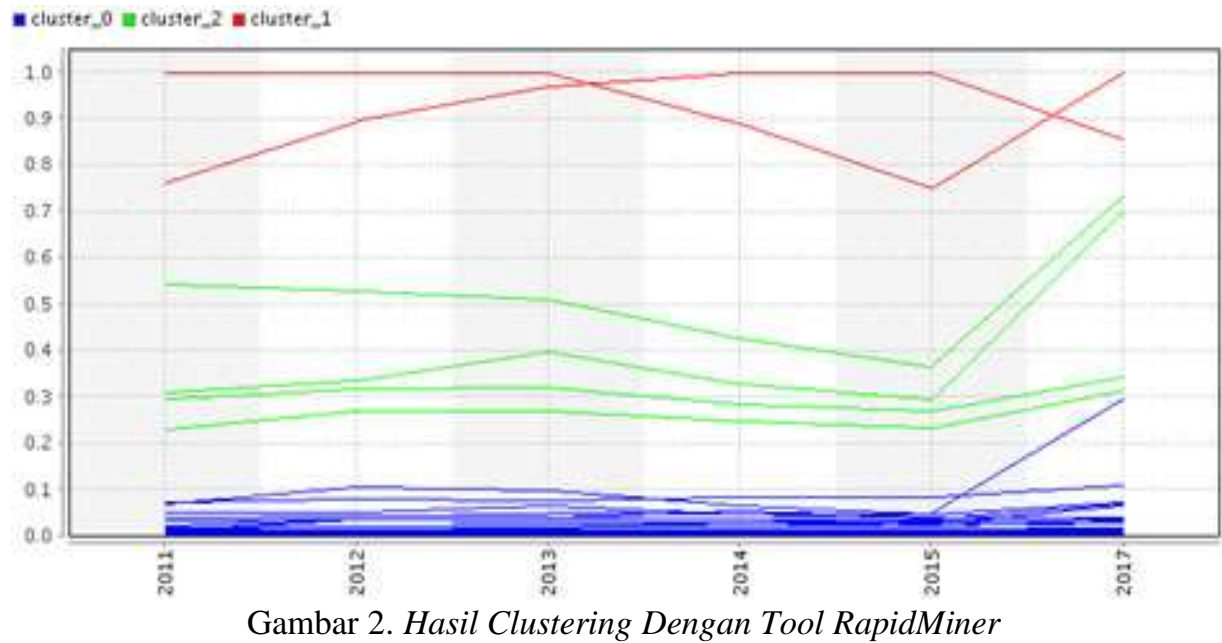

\subsection{Centroid Data}

Pada penggunaan algoritma k-means clustering dibutuhkan nilai titik pusat atau centroid yang digunakan sebagai data pusat dalam penentuan cluster yang diinginkan. Penentuan cluster dibagi ke dalam 3 tingkat yaitu cluster tingkat pembangkit tenaga listrik tinggi $(\mathrm{C} 1)$, cluster tingkat pembangkit tenaga listrik sedang (C2), dan cluster tingkat pembangkit tenaga listrik rendah (C3). Penentuan nilai centroid awal dengan menggunakan nilai jumlah daya atau kekuatan tenaga listrik $(\mathrm{GWh})$ pada 33 provinsi di Indonesia, sehingga diperoleh nilai centroid awal yang tertera pada tabel 3.

\begin{tabular}{lc}
\multicolumn{2}{c}{ Tabel 3. Centroid Awal (Iterasi 1) } \\
\hline Atribut & Nilai \\
\hline C1=nilai max & 321225.88 \\
C2=nilai average & 41067.58 \\
C3=nilai min & 105.51 \\
\hline
\end{tabular}

\subsection{Clustering Data}

Dengan penggunaan centroid awal, data dapat dicluster menjadi 3 (tiga) cluster yang telah ditentukan sebelumnya. Clustering merupakan proses mengekstrak data dengan cara mengambil nilai jarak terpendek dari hasil data yang diolah sehingga diperoleh nilai iterasi 1. Pada penelitian ini menghasilkan data baru yakni pembangkit tenaga listrik tinggi $(\mathrm{C} 1)$ ada pada 2 provinsi, pembangkit tenaga listrik rendah $(\mathrm{C} 2)$ terdapat pada 6 provinsi, dan pembangkit tenaga listrik rendah $(\mathrm{C} 3)$ berada di 25 provinsi yang diperoleh dari pengelompokan data pada iterasi 1 dengan menggunakan 3 (tiga) cluster. Hasil data lengkap dari perhitungan dan pengelompokan pada iterasi 1 dapat dilihat pada tabel 4 dan 5 .

Tabel 4. Perhitungan Jarak Pusat Cluster Iterasi 1

\begin{tabular}{lccccc}
\hline \multicolumn{1}{c}{ Provinsi } & \multicolumn{2}{c}{ Iterasi 1 } & & \\
& Jumlah Daya (GWh) & C1 & C2 & C3 & $\begin{array}{c}\text { Jarak } \\
\text { Terpendek }\end{array}$ \\
\hline Aceh & & & & & 3514.86 \\
Sumatera Utara & 3620.37 & 317605.51 & 37447.208 & 3514.86 & 3514.402 \\
Sumatera Barat & 104654.98 & 216570.9 & 63587.402 & 104549.47 & 63587.402 \\
Riau & 1093.95 & 320131.93 & 39973.628 & 988.44 & 988.44 \\
Jambi & 5083.95 & 316141.93 & 35983.628 & 4978.44 & 4978.44 \\
Sumatera Selatan & 650.86 & 320575.02 & 40416.718 & 545.35 & 545.35 \\
Bengkulu & 89668.66 & 231557.22 & 48601.082 & 89563.15 & 48601.082 \\
Lampung & 492.72 & 320733.16 & 40574.858 & 387.21 & 387.21 \\
Kep. Bangka Belitung & 475.4 & 320750.48 & 40592.178 & 369.89 & 369.89 \\
Kep. Riau & 4993.39 & 316232.49 & 36074.188 & 4887.88 & 4887.88 \\
DKI Jakarta & 15303.23 & 305922.65 & 25764.348 & 15197.72 & 15197.72 \\
Jawa Barat & 38121.7 & 283104.18 & 2945.8776 & 38016.19 & 2945.8776 \\
Jawa Tengah & 134353.44 & 186872.44 & 93285.862 & 134247.93 & 93285.862 \\
Di Yogyakarta & 175736.06 & 145489.82 & 134668.48 & 175630.55 & 134668.48 \\
Jawa Timur & 321225.88 & 0 & 280158.3 & 321120.37 & 0 \\
& 318723.28 & 2502.6 & 277655.7 & 318617.77 & 2502.6
\end{tabular}




Banten
Bali
Nusa Tenggara Barat
Nusa Tenggara Timur
Kalimantan Barat
Kalimantan Tengah
Kalimantan Selatan
Kalimantan Timur
Kalimantan Utara
Sulawesi Utara
Sulawesi Selatan
Sulawesi Tenggara
Gorontalo
Sulawesi Barat
Maluku
Maluku Utara
Papua Barat
Papua

12655.36
7986
4044.88
11807.56
3308.78
17457.75
18155.48
956.7
10703.59
7519.78
29431.75
3358.61
1276.39
105.51
3759.19
1056.81
2620.75
4827.3

$\begin{array}{cccc}308570.52 & 28412.218 & 12549.85 & 12549.85 \\ 313239.88 & 33081.578 & 7880.49 & 7880.49 \\ 317181 & 37022.698 & 3939.37 & 3939.37 \\ 309418.32 & 29260.018 & 11702.05 & 11702.05 \\ 317917.1 & 37758.798 & 3203.27 & 3203.27 \\ 303768.13 & 23609.828 & 17352.24 & 17352.24 \\ 303070.4 & 22912.098 & 18049.97 & 18049.97 \\ 320269.18 & 40110.878 & 851.19 & 851.19 \\ 310522.29 & 30363.988 & 10598.08 & 10598.08 \\ 313706.1 & 33547.798 & 7414.27 & 7414.27 \\ 291794.13 & 11635.828 & 29326.24 & 11635.828 \\ 317867.27 & 37708.968 & 3253.1 & 3253.1 \\ 319949.49 & 39791.188 & 1170.88 & 1170.88 \\ 321120.37 & 40962.068 & 0 & 0 \\ 317466.69 & 37308.388 & 3653.68 & 3653.68 \\ 320169.07 & 40010.768 & 951.3 & 951.3 \\ 318605.13 & 38446.828 & 2515.24 & 2515.24 \\ 316398.58 & 36240.278 & 4721.79 & 4721.79\end{array}$

Tabel 5. Hasil Pengelompokan Data Iterasi 1

\begin{tabular}{|c|c|c|c|c|c|c|c|}
\hline Provinsi & C1 & C2 & C3 & Provinsi & C1 & $\mathrm{C2}$ & $\mathbf{C 2}$ \\
\hline Aceh & & & 1 & Nusa Tenggara Timur & & & 1 \\
\hline Sumatera Utara & & 1 & & Kalimantan Barat & & & 1 \\
\hline Sumatera Barat & & & 1 & Kalimantan Tengah & & & 1 \\
\hline Riau & & & 1 & Kalimantan Selatan & & & 1 \\
\hline Jambi & & & 1 & Kalimantan Timur & & & 1 \\
\hline Sumatera Selatan & & 1 & & Kalimantan Utara & & & 1 \\
\hline Bengkulu & & & 1 & Sulawesi Utara & & & 1 \\
\hline Lampung & & & 1 & Sulawesi Tengah & & & 1 \\
\hline Kep. Bangka Belitung & & & 1 & Sulawesi Selatan & & 1 & \\
\hline Kep. Riau & & & 1 & Sulawesi Tenggara & & & 1 \\
\hline DKI Jakarta & & 1 & & Gorontalo & & & 1 \\
\hline Jawa Barat & & 1 & & Sulawesi Barat & & & 1 \\
\hline Jawa Tengah & & 1 & & Maluku & & & 1 \\
\hline Jawa Timur & 1 & & & Maluku Utara & & & 1 \\
\hline Banten & 1 & & & Papua Barat & & & 1 \\
\hline Bali & & & 1 & Papua & & & 1 \\
\hline Nusa Tenggara Barat & & & 1 & & & & \\
\hline
\end{tabular}

Proses clusterisasi pada algoritma k-means akan terus berlangsung sampai pengelompokan iterasi sebelum dan iterasi sesudahnya sama. Pada iterasi ke-2 dan seterusnya proses clusterisasi data akan berlangsung kembali dengan centroid baru yakni hasil dari perhitungan iterasi 1 atau iterasi sebelumnya. Hasil Pengelompokan data pada iterasi 1 dapat dilihat pada tabel dan selanjutnya perhitungan clustering iterasi 2 dapat dilihat pada tabel 6-8.

\begin{tabular}{lc}
\multicolumn{2}{c}{ Tabel 6. Centroid Data Iterasi 2 } \\
\hline \multicolumn{1}{c}{ Atribut } & Nilai \\
\hline C1=nilai max & 319974.58 \\
C2=nilai average & 95327.765 \\
C3=nilai min & 5732.5724 \\
\hline
\end{tabular}

Tabel 7. Perhitungan Jarak Cluster Pusat Iterasi 2

\begin{tabular}{lccccc}
\hline \multicolumn{1}{c}{ Provinsi } & Jumlah Daya (GWh) & C1 & C2 & C3 & $\begin{array}{c}\text { Jarak } \\
\text { Terpendek }\end{array}$ \\
\hline Aceh & & & & 2112.2 \\
Sumatera Utara & 3620.37 & 316354.21 & 91707.4 & 2112.2 & 9327.21 \\
Sumatera Barat & 104654.98 & 215319.6 & 9327.21 & 98922.41 & 4638.62 \\
Riau & 1093.95 & 318880.63 & 94233.82 & 4638.62 & 648.62 \\
Jambi & 5083.95 & 314890.63 & 90243.82 & 648.62 & 5081.71 \\
Sumatera Selatan & 650.86 & 319323.72 & 94676.91 & 5081.71 & 5659.11 \\
Bengkulu & 89668.66 & 230305.92 & 5659.11 & 83936.09 & 5239.85 \\
Lampung & 492.72 & 319481.86 & 94835.05 & 5239.85 & 5257.17 \\
Kep. Bangka Belitung & 475.4 & 319499.18 & 94852.37 & 5257.17 & 739.18
\end{tabular}




\begin{tabular}{|c|c|c|c|c|c|c|c|c|}
\hline \multicolumn{2}{|l|}{ Kep. Riau } & \multicolumn{2}{|c|}{15303.23} & \multicolumn{2}{|c|}{304671.35} & 80024.54 & \multicolumn{2}{|l|}{9570.66} \\
\hline \multicolumn{2}{|l|}{ DKI Jakarta } & \multicolumn{2}{|c|}{38121.7} & \multicolumn{2}{|c|}{281852.88} & 57206.07 & \multicolumn{2}{|l|}{32389.13} \\
\hline \multicolumn{2}{|l|}{ Jawa Barat } & \multicolumn{2}{|c|}{134353.44} & \multicolumn{2}{|c|}{185621.14} & 39025.68 & \multicolumn{2}{|l|}{128620.87} \\
\hline \multicolumn{2}{|c|}{ Jawa Tengah } & \multicolumn{2}{|c|}{175736.06} & \multicolumn{2}{|c|}{144238.52} & 80408.3 & \multicolumn{2}{|l|}{170003.49} \\
\hline \multicolumn{2}{|c|}{ Jawa Timur } & \multicolumn{2}{|c|}{321225.88} & \multicolumn{2}{|c|}{1251.3} & 225898.12 & \multicolumn{2}{|l|}{315493.31} \\
\hline \multicolumn{2}{|l|}{ Banten } & \multicolumn{2}{|c|}{318723.28} & \multicolumn{2}{|c|}{1251.3} & 223395.52 & 312990.71 & \\
\hline Bali & & 5.36 & & & 319.22 & 82672.41 & 6922.79 & \\
\hline Nusa Tengg & ara Barat & 86 & & & 988.58 & 87341.77 & 2253.43 & \\
\hline Nusa Tengg & ara Timur & 4.88 & & & 5929.7 & 91282.89 & 1687.69 & \\
\hline Kalimantan & Barat & 7.56 & & & 167.02 & 83520.21 & 6074.99 & \\
\hline Kalimantan & Tengah & 8.78 & & & 6665.8 & 92018.99 & 2423.79 & \\
\hline Kalimantan & Selatan & 7.75 & & & 516.83 & 77870.02 & 11725.18 & \\
\hline Kalimantan & Timur & 5.48 & & & 1819.1 & 77172.29 & 12422.91 & \\
\hline Kalimantan & Utara & 6.7 & & & 017.88 & 94371.07 & 4775.87 & \\
\hline Sulawesi U & ara & 3.59 & & & 270.99 & 84624.18 & 4971.02 & \\
\hline Sulawesi T & ngah & 9.78 & & & 2454.8 & 87807.99 & 1787.21 & \\
\hline Sulawesi S & latan & 1.75 & & & 542.83 & 65896.02 & 23699.18 & \\
\hline Sulawesi T & nggara & 8.61 & & & 615.97 & 91969.16 & 2373.96 & \\
\hline Gorontalo & & 6.39 & & & 698.19 & 94051.38 & 4456.18 & \\
\hline Sulawesi B & & .51 & & & 869.07 & 95222.26 & 5627.06 & \\
\hline Maluku & & 9.19 & & & 215.39 & 91568.58 & 1973.38 & \\
\hline Maluku Uta & & 6.81 & & & 917.77 & 94270.96 & 4675.76 & \\
\hline Papua Bara & & 0.75 & & & 353.83 & 92707.02 & 3111.82 & \\
\hline Papua & & 7.3 & & & 147.28 & 90500.47 & 905.27 & \\
\hline & & & & Fe & JUN & ata Iterasi 2 & & \\
\hline & Provinsi & C1 & $\mathrm{C2}$ & C3 & & rovinsi & C1 & $\mathrm{C2}$ \\
\hline & Aceh & & & 1 & Nusa $T e$ & enggara Timur & & 1 \\
\hline & Sumatera Utara & & 1 & & Kalimar & tan Barat & & 1 \\
\hline & Sumatera Barat & & & 1 & Kalimar & tan Tengah & & 1 \\
\hline & Riau & & & 1 & Kalimar & tan Selatan & & 1 \\
\hline & Jambi & & & 1 & Kalimar & tan Timur & & 1 \\
\hline & Sumatera Selatan & & 1 & & Kalimar & tan Utara & & 1 \\
\hline & Bengkulu & & & 1 & Sulawes & i Utara & & 1 \\
\hline & Lampung & & & 1 & Sulawes & i Tengah & & 1 \\
\hline & Kep. Bangka Belitung & & & 1 & Sulawes & i Selatan & & 1 \\
\hline & Kep. Riau & & & 1 & Sulawes & i Tenggara & & 1 \\
\hline & Dki Jakarta & & & 1 & Goronta & & & 1 \\
\hline & Jawa Barat & & 1 & & Sulawes & i Barat & & 1 \\
\hline & Jawa Tengah & & 1 & & Maluku & & & 1 \\
\hline & Jawa Timur & 1 & & & Maluku & Utara & & 1 \\
\hline & Banten & 1 & & & Papua B & arat & & 1 \\
\hline & Bali & & & 1 & Papua & & & 1 \\
\hline & Nusa Tenggara Barat & & & 1 & & & & \\
\hline
\end{tabular}

Pengelompokan data pada iterasi 2 berbeda hasilnya dengan pengelompokan data iterasi 1. Pada iterasi 2 diperoleh hasil pengelompokan data yaitu cluster tinggi (C1) sebanyak 2 provinsi yakni Jawa Timur dan Banten, cluster sedang sebanyak 4 provinsi yakni Sumatera Utara, Sumatera Selatan, Jawa Barat dan Jawa Tengah, sedangkan cluster rendah (C3) ada pada 27 provinsi lainnya. Proses clusterisasi harus tetap berlangsung kembali dengan mencari nilai centroid atau titik pusat untuk perhitungan iterasi selanjutnya dari hasil clusterisasi data pada iterasi 2 . Proses penentuan jarak terdekat dan clusterisasi data pada iterasi terakhir (3) dapat dilihat pada tabel berikut:

\begin{tabular}{lc}
\multicolumn{2}{c}{ Tabel 9. Centroid Data Iterasi 3 } \\
\hline \multicolumn{1}{c}{ Atribut } & Nilai \\
\hline C1=nilai max & 319974.58 \\
C2=nilai average & 126103.29 \\
C3=nilai min & 7809.92 \\
\hline
\end{tabular}

Tabel 10. Perhitungan Jarak Cluster Iterasi 3

\begin{tabular}{|c|c|c|c|c|c|}
\hline \multicolumn{6}{|c|}{ Iterasi 3} \\
\hline Provinsi & Jumlah Daya (GWh) & C1 & $\mathrm{C2}$ & $\mathbf{C 3}$ & $\begin{array}{c}\text { Jarak } \\
\text { Terpendek }\end{array}$ \\
\hline Aceh & 3620.37 & 316354.21 & 122482.92 & 4189.547 & 4189.547 \\
\hline Sumatera Utara & 104654.98 & 215319.6 & 21448.305 & 96845.063 & 21448.305 \\
\hline Sumatera Barat & 1093.95 & 318880.63 & 125009.34 & 6715.967 & 6715.967 \\
\hline Riau & 5083.95 & 314890.63 & 121019.34 & 2725.967 & 2725.967 \\
\hline
\end{tabular}




\begin{tabular}{|c|c|c|c|c|c|c|c|}
\hline Jambi & \multicolumn{2}{|l|}{650.86} & & 19323.72 & 125452.43 & 7159.057 & \\
\hline Sumatera Selatan & \multicolumn{2}{|c|}{89668.66} & & 30305.92 & 36434.625 & 81858.743 & \\
\hline Bengkulu & \multicolumn{2}{|c|}{492.72} & & 19481.86 & 125610.57 & 7317.197 & \\
\hline Lampung & \multicolumn{2}{|l|}{475.4} & & 19499.18 & 125627.89 & 7334.517 & \\
\hline Kep. Bangka Belitung & \multicolumn{2}{|c|}{4993.39} & & 14981.19 & 121109.9 & 2816.527 & \\
\hline Kep. Riau & \multicolumn{2}{|c|}{15303.23} & & 04671.35 & 110800.06 & 7493.313 & \\
\hline DKI Jakarta & \multicolumn{2}{|c|}{38121.7} & & 81852.88 & 87981.585 & 30311.783 & \\
\hline Jawa Barat & \multicolumn{2}{|c|}{134353.44} & & 85621.14 & 8250.155 & 126543.52 & \\
\hline Jawa Tengah & \multicolumn{2}{|c|}{175736.06} & & 44238.52 & 49632.775 & 167926.14 & \\
\hline Di Yogyakarta & \multicolumn{2}{|c|}{321225.88} & & 1251.3 & 195122.6 & 313415.96 & \\
\hline Jawa Timur & 318723.2 & & & 1251.3 & 192620 & 310913.36 & \\
\hline Banten & 12655.3 & & & 07319.22 & 113447.93 & 4845.443 & \\
\hline Bali & 7986 & & & 11988.58 & 118117.29 & 176.08296 & \\
\hline Nusa Tenggara Barat & 4044.88 & & & 315929.7 & 122058.41 & 3765.037 & \\
\hline Nusa Tenggara Timur & 11807.5 & & & 08167.02 & 114295.73 & 3997.643 & \\
\hline Kalimantan Barat & 3308.78 & & & 316665.8 & 122794.51 & 4501.137 & \\
\hline Kalimantan Tengah & 17457.7 & & & 02516.83 & 108645.54 & 9647.833 & \\
\hline Kalimantan Selatan & 18155.4 & & & 301819.1 & 107947.81 & 10345.563 & \\
\hline Kalimantan Timur & 956.7 & & & 19017.88 & 125146.59 & 6853.217 & \\
\hline Kalimantan Utara & 10703.5 & & & 09270.99 & 115399.7 & 2893.673 & \\
\hline Sulawesi Utara & 7519.78 & & & 312454.8 & 118583.51 & 290.13704 & \\
\hline Sulawesi Selatan & 29431.7 & & & 90542.83 & 96671.535 & 21621.833 & \\
\hline Sulawesi Tenggara & 3358.61 & & & 16615.97 & 122744.68 & 4451.307 & \\
\hline Gorontalo & 1276.39 & & & 18698.19 & 124826.9 & 6533.527 & \\
\hline Sulawesi Barat & 105.51 & & & 19869.07 & 125997.78 & 7704.407 & \\
\hline Maluku & 3759.19 & & & 16215.39 & 122344.1 & 4050.727 & \\
\hline Maluku Utara & 1056.81 & & & 18917.77 & 125046.48 & 6753.107 & \\
\hline Papua Barat & 2620.75 & & & 17353.83 & 123482.54 & 5189.167 & \\
\hline Papua & 4827.3 & & & 15147.28 & 121275.99 & 2982.617 & \\
\hline & $\mathrm{HC}$ & & & pokan & ta Iterasi 3 & & \\
\hline Provinsi & C1 & $\mathrm{C2}$ & $\mathrm{C3}$ & & ovinsi & C1 $\mathrm{C2}$ & $\mathbf{C 2}$ \\
\hline Aceh & & & 1 & Nusa Ter & ggara Timur & & 1 \\
\hline Sumatera Utara & & 1 & & Kaliman & an Barat & & 1 \\
\hline Sumatera Barat & & & 1 & Kalimant & an Tengah & & 1 \\
\hline Riau & & & 1 & Kalimant & an Selatan & & 1 \\
\hline Jambi & & & 1 & Kalimant & an Timur & & 1 \\
\hline Sumatera Selatan & & 1 & & Kalimant & an Utara & & 1 \\
\hline Bengkulu & & & 1 & Sulawesi & Utara & & 1 \\
\hline Lampung & & & 1 & Sulawesi & Tengah & & 1 \\
\hline Kep. Bangka Belitung & & & 1 & Sulawesi & Selatan & & 1 \\
\hline Kep. Riau & & & 1 & Sulawesi & Tenggara & & 1 \\
\hline DKI Jakarta & & & 1 & Gorontal & & & 1 \\
\hline Jawa Barat & & 1 & & Sulawesi & Barat & & 1 \\
\hline Jawa Tengah & & 1 & & Maluku & & & 1 \\
\hline Jawa Timur & 1 & & & Maluku & Itara & & 1 \\
\hline Banten & 1 & & & Papua B & & & 1 \\
\hline Bali & & & 1 & Papua & & & 1 \\
\hline Nusa Tenggara Barat & & & 1 & & & & \\
\hline
\end{tabular}

Pada iterasi 3, proses clusterisasi atau pengelompokan data yang telah dilakukan dengan menggunakan 3 cluster dari iterasi 1 bernilai sama dengan pengelompokan data pada iterasi 2. Maka proses clusterisasi data pada kasus Tenaga Listrik yang Dibangkitkan Berdasarkan Provinsi berhenti.

\section{KESIMPULAN}

Berdasarkan hasil penilaian terhadap kasus Tenaga Listrik yang Dibangkitkan Berdasarkan Provinsi dapat menerapkan datamining k-means clustering sebagai teknik penyelesaian masalah. Sumber data diperoleh dari situs resmi nasional http://www.bps.go.id kemudian data tersebut diolah dengan software Micrososft Excel untuk menentukan titik pusat data (centroid) pada 3 cluster data dan menghasilkan 3 iterasi. Sehingga hasil akhir diperoleh penilaian Jumlah Tenaga Listrik yang Dibangkitkan Berdasarkan Provinsi di Indonesia yakni: provinsi cluster tinggi sebanyak 2 provinsi yaitu Jawa Timur dan Banten, provinsi cluster sedang sebanyak 4 provinsi yaitu Sumatera Utara, Sumatera Selatan, Jawa Barat dan Jawa Tengah sedangkan provinsi cluster rendah sebanyak 27 di provinsi lainnya. Hasil analisis dari penelitian ini dapat dijadikan sebagai masukan bagi pemerintah dan Perusahaan Listrik Negara (PLN), agar menjadikan provinsi kategori cluster terendah sebagai prioritas utama dalam meningkatkan 
pertumbuhan pembangkit tenaga listrik serta lebih interaktif dalam pemanfaatan energi listrik secara efektif dan efisien.

\section{REFRENCES}

[1] Aline Embun Pramadhani and T. Setiadi, "Penerapan Data Mining Untuk Klasifikasi Prediksi Penyakit ISPA (Infeksi Saluran Pernapasan Akut) Dengan Algoritma Decision Tree (ID3)," J. Sarj. Tek. Inform., vol. 2, no. 1, pp. 831-839, 2014.

[2] I. Parlina, A. P. Windarto, A. Wanto, and M. R. Lubis, "Memanfaatkan Algoritma K-Means Dalam Menentukan Pegawai Yang Layak Mengikuti Asessment Center Untuk Clustering Program SDP,” CESS (Journal Comput. Eng. Syst. Sci., vol. 3, no. 1, pp. 87-93, 2018.

[3] A. P. Windarto, "Implementation of Data Mining on Rice Imports by Major Country of Origin Implementation of Data Mining on Rice Imports by Major Country of Origin Using Algorithm Using K-Means Clustering Method," Int. J. Artif. Intelegence Res., vol. 1, no. 2, pp. 26-33, 2017.

[4] H. Santosa, “Aplikasi Penentuan Tarif Listrik Menggunakan Metode Fuzzy Sugeno," J. Sist. Inf. Bisnis, vol. 01, no. 14, pp. 28-39, 2014

[5] A. Widarma and H. Kumala, "Sistem Pendukung Keputusan Dalam Menentukan Pengguna Listrik Subsidi Dan Nonsubsidi Menggunakan Metode Fuzzy Mamdani ( Studi Kasus : PT . PLN Tanjung Balai ),” J. Teknol. Inf., vol. 2, no. 2, pp. 165-171, 2018.

[6] D. Despa et al., "Prediksi kebutuhan listrik tiga fase dengan jaringan syaraf tiruan berdasarkan data erte system universitas lampung," SEBATIK, pp. 203-210, 2019.

[7] I. Sudono et al., "Pengelompokan Produksi Padi Nasional Dengan Pendekatan Data Mining Konsep K-Means Clustering National Rice Production In Mining Data Approach Concept Of K-Means,” J. Irig., vol. 8, no. 2, pp. 72-89, 2013.

[8] A. P. Windarto, P. Studi, S. Informasi, and D. Mining, "Penerapan Data Mining Pada Ekspor Buah-Buahan Menurut Negara Tujuan Menggunakan K-Means Clustering," NTechno.COM, vol. 16, no. 4, pp. 348-357, 2017.

[9] N. H. Kristanto, A. C. L. A, and H. B. S, "Implemantasi K-Means Clustering untuk Pengelompokan Analisis Rasio Profitabilitas dalam Working Capital,” JUISI, vol. 02, no. 01, pp. 9-15, 2016. 